\title{
SISTEM INFORMASI MANAJEMEN DATA SURAT BERBASIS WEB PADA KANTOR DINAS PERTANIAN KOTA TERNATE
}

\section{WEB-BASED LETTER MANAGEMENT INFORMATION SYSTEM THE DEPARTMENT OF AGRICULTURE OF CITY TERNATE}

\author{
Zulaifa Rumaf ${ }^{1}$, Ilham Djufri ${ }^{2}$, Junaidi Sabtu ${ }^{3}$ \\ ${ }^{1,3}$ Program Studi Manajemen Informatika, ${ }^{2}$ Program Studi Teknik Komputer \\ Akademi Ilmu Komputer Ternate \\ zulaifarumaf01@yahoo.com
}

\begin{abstract}
Abstrak
Dalam pengolahan data surat masuk dan keluar pada Dinas Pertanian Kota Ternate saat ini masih dilakukan dengan cara manual yaitu dicatat pada sebuah buku dan disimpan dalam bentuk hardcopy di dalam lemari arsip tanpa dikelompokan untuk setiap jenis surat. Dari proses pengolahan data surat yang seperti ini menimbulkan beberapa masalah diantaranya adalah dengan semakin banyaknya surat masuk dan surat keluar mengakibatkan terjadinya penumpukan catatan dan penumpukan arsip, Hal ini menyebabkan dibutuhkannya waktu lebih untuk mencari kembali surat yang sudah diarsipkan dan juga mengakibatkan kesulitan dalam proses pencarian data-data surat yang sudah lama.Tujuan merancang aplikasi ini agar memudahkan proses pengolahan data surat masuk dan surat keluar. Perancangan aplikasi surat masuk dan surat keluar ini dibuat dengan menggunakan tools seperti PHPMyAdmin, MySQL sebagai database dan Xampp sebagai server offlinenya, dan dapat disimpulkan bahwa dalam perancangan aplikasi ini memberikan banyak kemudahan dalam proses pengolahan data surat.
\end{abstract}

\section{Kata Kunci: Surat, PHPMyAdmin, MySQL, Xampp, Dinas Pertanian}

\begin{abstract}
In processing the data of incoming and outgoing letters at the Agriculture Office of Ternate City is currently still done manually, which is recorded in a book and stored in hard copy in a filing cabinet without grouping for each type of letter. From the letter data processing process like this raises several problems including the increasing number of incoming and outgoing messages resulting in a buildup of records and accumulation of archives, this causes more time to search for archived letters and also causes difficulties in the data search process. Dates of old letters. The purpose of designing this application is to facilitate the data processing of incoming and outgoing mail. The design of the application for incoming and outgoing mail is made, by using tools such as PHPMyAdmin, MySQL as the database and XAMPP as the more offline server, and it can be, included that in designing this application provides a lot of convenience in the data processing of letters.
\end{abstract}

Keywords: Mail, PHPMyAdmin, MySQL, XAMPP, Agriculture Department 


\section{PENDAHULUAN}

Pada era globalisasi Teknologi Komputer memegang peranan yang sangat penting untuk membantu proses aktivitas kerja di diperkantoran baik pemerintah maupun swasta. Proses pertukaran Informasi menjadi sesuatu yang penting dalam membantu kelancaran kegiatan pengadminstrasian khususnya kegiatan administrasi yang berkaitan dengan aktivitas surat-menyurat (Rahmah, 2014).

Dinas Pertanian Kota Ternate merupakan salah satu kantor pemerintah yang tidak terlepas dari kegiatan surat menyurat sebagai sarana komunikasi dengan pihak internal dan eksternal, dalam pertahun jumlah surat masuk dan surat keluar pada Dinas Pertanian Kota Ternate diperkirakan mencapai hingga 1000 (seribu) lebih, hal ini membuat pengolahan surat masuk dan surat keluar menjadi meningkat pula, sedangkan saat ini pengolahan Data surat masuk dan surat keluar masih dilakukan dengan cara manual yaitu dicatat pada sebuah buku dan disimpan dalam bentuk hardcopy di dalam lemari arsip tanpa dikelompokan untuk setiap jenis surat.

Maka dengan memanfaatkan Teknologi berbasis website bisa dimungkinkan penyimpanan arsip-arsip surat masuk dan surat keluar bisa dengan mudah, akurat dan tahan lama meskipun sudah setahun yang lalu. Penyimpanan arsip-arsip tersebut akan berupa file atau softcopy sehingga memungkinkan kemudahan dan kenyamanan dalam hal pencarian dan tidak rusak dimakan waktu. (Masykur F, dkk, 2015).

Berdasarkan hal tersebut, maka penulis tertarik untuk melakukan penelitian dan pembuatan Sistem Informasi yang baru yaitu berbasis web dengan tujuan mengembangkan Sistem yang ber berjalan saat ini.

\section{Rumusan Masalah}

Bagaimana membuat Sistem Informasi Manajemen Surat berbasis web pada Dinas Pertanian Kota Ternate? Dengan Tujuan Agar mempermudah pegawai ataupun pimpinan dalam mengolah surat masuk dan surat keluar maupun mempermudah dalam pengarsipan persuratan.

\section{LANDASAN TEORI \\ Pengertian Sistem}

Sistem merupakan jaringan dari elemenelemen yang saling berhubungan, membentuk suatu kesatuan untuk melaksakan suatu tujuan pokok dari Sistem tersebut.

Tujuan pokok dari Sistem Komputer dalam mengolah Data menghasilkan Informasi. Sistem yang dimaksud adalah kombinasi antara prosedur kerja, Informasi, orang dan teknologi Informasi yang diorganisasikan untuk mencapai tujuan dalam organisasi (Kadir, 2014). Sistem adalah sebuah tatanan (keterpaduan) yang terdiri atas sejumlah komponen fungsional (dengan satuan fungsi dan tugas khusus) yang saling berhubungan dan secara bersama-sama bertujuan untuk memenuhi suatu proses tertentu (Fathansyah, 2015).

\section{Pengertian Informasi dan Data}

Informasi adalah sebuah istilah yang tepat dalam pemakaian umum. Informasi dapat mengenai Data mentah, Data tersusun, kapasitas sebuah saluran komunikasi, dan lain sebagainya (Sutabri, 2012).

Data merupakan fakta atau bagian dari fakta yang mengandung arti, yang dihub- 
ungkan dengan kenyataan, gambar-gambar, kata-kata, angka-angka, huruf atau simbolsimbol menyatakan suatu ide objek kondisi atau situasi dan lain-lain (Fatansyah, 2015).

\section{Pengertian Sistem Informasi}

Sistem Informasi adalah suatu Sistem dlam suatu organisasi yang mempertemukan kebutuhan pengolahan transaksi harian yang mendukung fungsi operasi organisasi yang bersifat manajerial dengan kegiatan strategi dari suatu organisasi untuk dapat menyediakan kepada pihak luar tertentu dengan laporan yang diperlukan (Sutabri, 2012).

\section{Pengertian Surat}

Surat masuk adalah semua jenis surat yang diterima dari organisasi/instansi maupun perorangan, baik yang diterima melalui pos (kantor pos), maupun yang diterima dari kurir (pengantar surat) dengan mempergunakan buku pengiriman (Wursanto, 1991).

Surat keluar yaitu surat yang dikirim dari pihak baik instansi, atau organisasi yang berisi tentang suatu Informasi atau Data baik itu perintah, pemberitahuan maupun Informasi lainnya. Surat keluar adalah surat yang sudah lengkap (bertanggal, bernomor, berstempel dan telah ditandatangani oleh yang berwenang yang dibuat oleh suatu instansi (Wursanto, 1991).

\section{PHP dan MySQL}

PHP adalah bahasa pemograman web server-side yang bersifat open source. PHP adalah skrip yang digunakan untuk membuat halaman website yang dinamis. Dinamis berarti halaman yang akan ditampilkan dibuat saat halaman itu diminta oleh client. Semua skrip PHP dieksekusi pada server dimana skrip tersebut dijalankan (Anhar, 2010).

MySQL merupakan software yang tergolong sebagai Database Management System (DBMS) yang bersifat open source. Software ini dilengkapi dengan source code, selain tentu saja bentuk executable-nya atau kode yang dapat dijalankan secara langsung dalam Sistem operasi, dan bisa diperoleh dengan cara mengunduh di Internet secara gratis (Anhar, 2010).

\section{METODE PENELITIAN}

\section{Metode Pegumpulan Data}

1. Studi pustaka ini dilakukan dengan mendapatkan Data-Data berupa buku, jurnal berkaitan dengan program aplikasi yang akan dibuat.

2. Observasi, yaitu pengamatan langsung terhadap mekanisme Sistem yang sedang berjalan di Kantor Dinas Pertanian Kota Ternate.

3. Wawancara (interview), yaitu pengumpulan Data berdasarkan tatap muka dan tanya-jawab dengan pegawai agar memperoleh Informasi yang akurat.

\section{Kerangka Berpikir}

Pengolahan Data Surat Masuk pada Surat Keluar pada Dinas Pertanian Kota Ternate masih dilakukan dengan cara manual yaitu

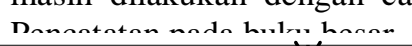
Analisis Permasalahan

Perancangan Website Pengolahan Data Surat Masuk dan Surat Keluar

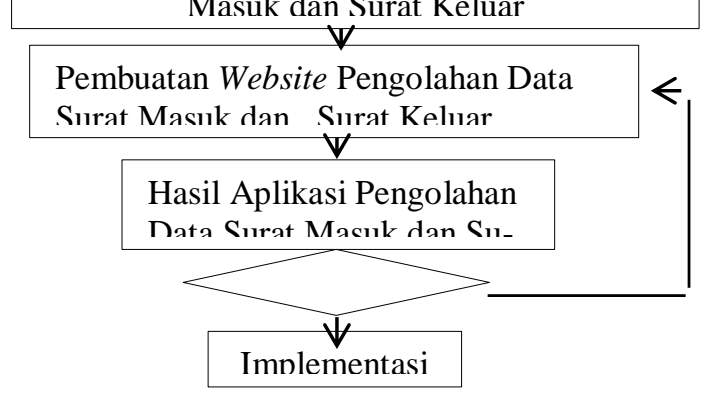

Volume 4 Nomor 2 | September 2019 
Gambar 1. Kerangka Berpikir

\section{Alat Bahan Penelitian}

Maksud alat penelitian disini menerangkan komponen hardware dan software yang digunakan sebagai alat dalam mendukung penelitian yang dilakukan, juga sebagai alat pengolahan Data dan pembuata Sistem yang akan dirancang.

Tabel 1. Daftar Perangkat

\begin{tabular}{|l|l|}
\hline Perangkat & Spesifikasi \\
\hline \multirow{4}{*}{$\begin{array}{l}\text { Personal } \\
\text { Computer }\end{array}$} & $\begin{array}{l}\text { Prossesor: Intel Celeron } \\
\text { N3350 1.10 GHz }\end{array}$ \\
\cline { 2 - 2 } & Memori:1.83 GB RAM \\
\cline { 2 - 2 } & $\begin{array}{l}\text { Sistem Operasi: Windows 10 } \\
\text { Pro 64 bit }\end{array}$ \\
\cline { 2 - 2 } & $\begin{array}{l}\text { Merk: Lenovo Frekuensi 63 } \\
\text { Hz }\end{array}$ \\
\hline Browser & $\begin{array}{l}\text { Google Chrome version } \\
\text { 66.0.3359.181 }\end{array}$ \\
\hline Printer & Canon iP2700 \\
\hline \multirow{3}{*}{ Tools } & \multicolumn{2}{|l|}{} \\
\hline Webserver & Apache 2.4.29 \\
\hline $\begin{array}{l}\text { Bahasa } \\
\text { pemrograman }\end{array}$ & PHP versi 7.1 .11 \\
\hline Database & MYSQL \\
\hline $\begin{array}{l}\text { Database } \\
\text { Management }\end{array}$ & $\begin{array}{l}\text { PHP MyAdmin } \\
\text { versi 4.7.4 }\end{array}$ \\
\hline Editor & $\begin{array}{l}\text { Sublime } 3 \text { dan } \\
\text { Visio 2013 }\end{array}$ \\
\hline
\end{tabular}

\section{ANALISIS DAN PERANCANGAN}

\section{Analisis Sistem}

Secara umum perancangan Sistem merupakan sebuah proses yang terdiri dari beberapa kegiatan. Pertama adalah memunculkan secara tepat dan rinci operasional manajemen yang berkaitan dengan kegiatan pengolahan Data yang dikehendaki oleh manajemen sebenarnya. Tujuan akhir adalah untuk mengurangi fungsi-fungsi yang teraplikasi, baik dalam hal tujuan, operasional, Data, faktor-faktor serta laporannya.

Perancangan Sistem adalah suatu pendekatan yang Sistematis untuk mengidentifikasi suatu masalah, peluang, tujuan-tujuan, menganalisis arus Informasi serta untuk merancang Sistem Informasi terKomputerisasi untuk menyelesaikan masalah (Nugroho, 2004).

Rancangan Sistem adalah penentu spesifikasi yang memenuhi kebutuhan dan persyaratan yang ditentukan selama tahap analisis Sistem.

Perancangan sistem termasuk pada aliran proses pengolahan surat masuk dan surat keluar. Flowchart surat masuk dan surat keluar bisa dilihat pada gambar 4.2 dan gambar di bawah ini.

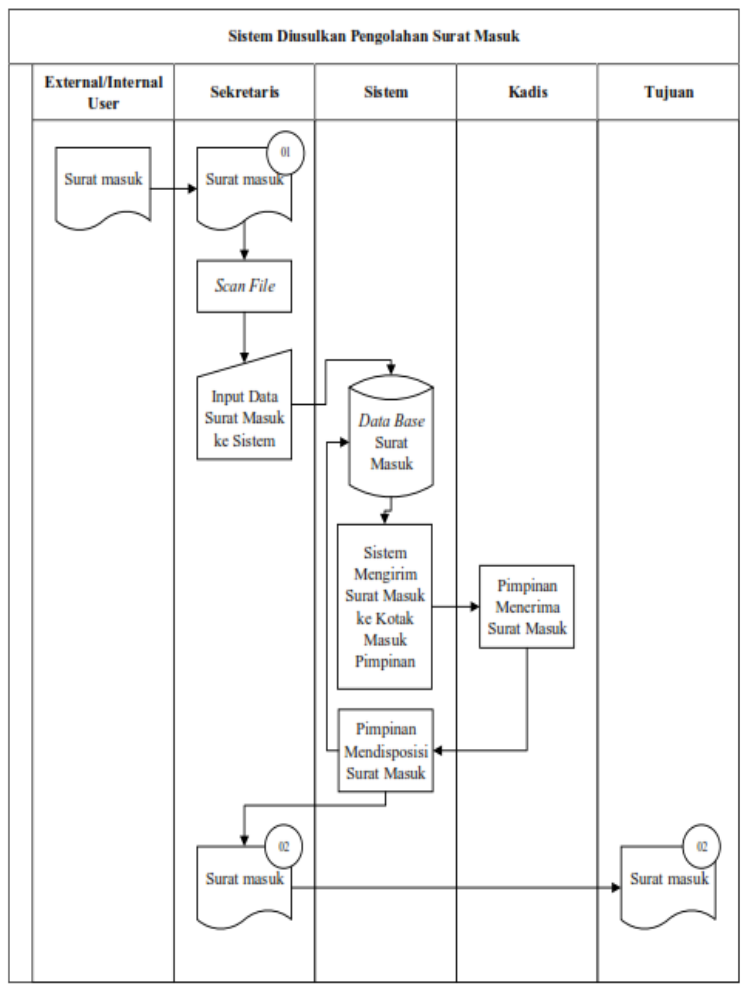

Gambar 2. Sistem Diusulkan Analisis Surat Masuk 


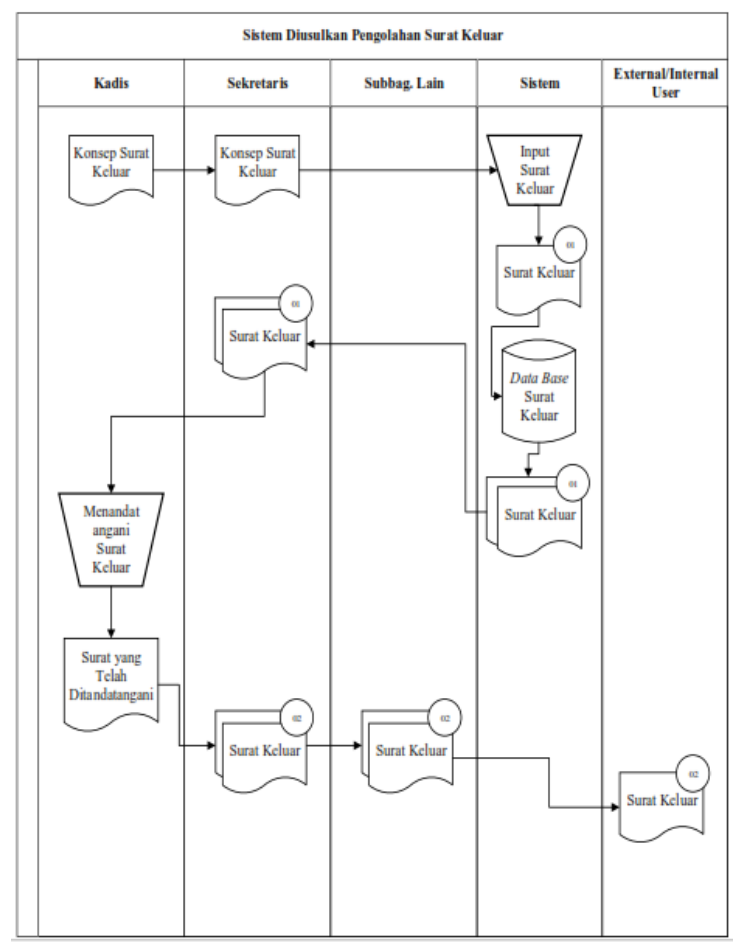

Gambar 3. Sistem Diusulkan Analisis Surat Keluar

\section{Perancangan Sistem \\ Diagram Arus Data}

Merupakan alur yang menunjukan secara keseluruhan Sistem secara garis besar. Koneks diagram ini menampilkan proses yang berinteraksi dengan lingkungannya baik dari luar dan pihak dalam dari Sistem.
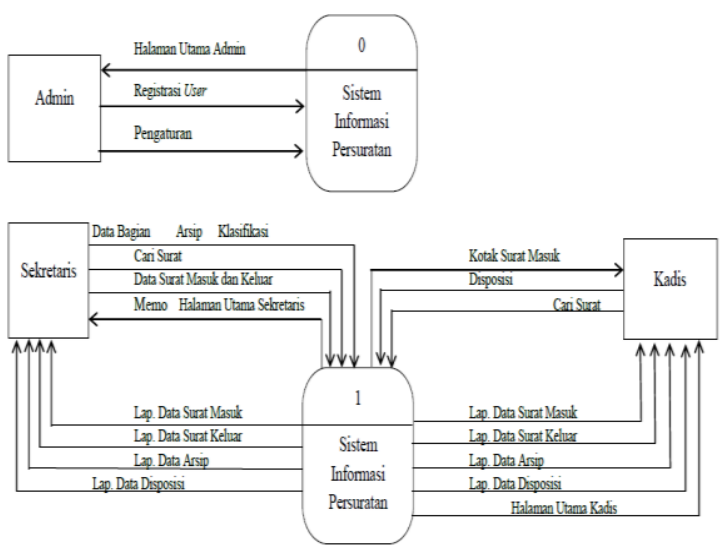

Gambar 4 Diagram Konteks

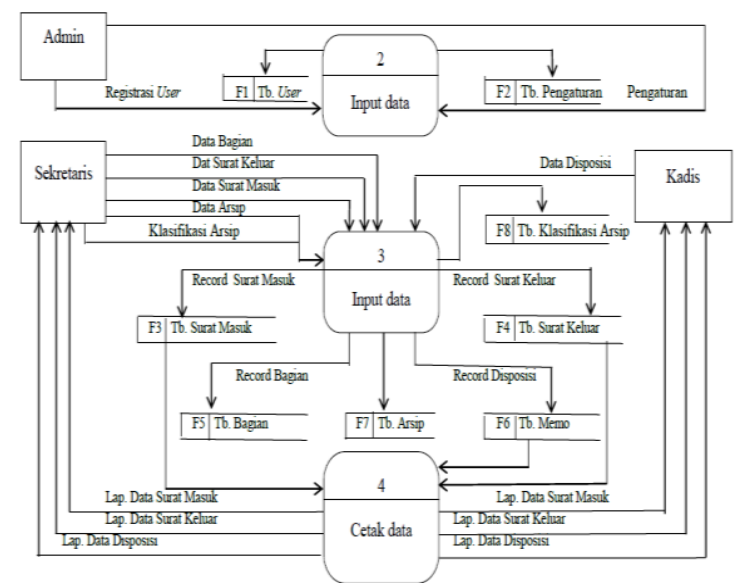

Gambar 5. DAD Level 0

Diagram level 1 (satu) dan 2 (dua) adalah diagram yang menggambarkan secara rinci dari proses input dan cetak Data.

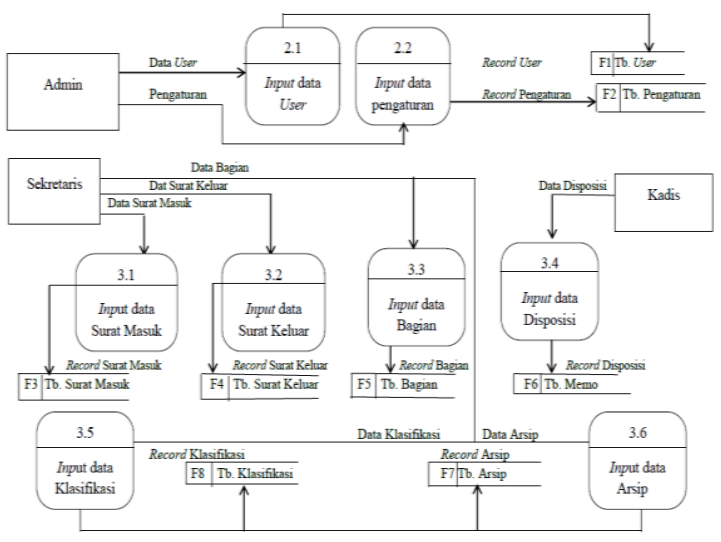

Gambar 6. DAD Level 1 Proses Input

\section{Entity Relation diagram (ERD)}

ERD merupakan model jaringan Data yang menekankan pada struktur-struktur dan relationship Data. Dalam penelitian ini ERD akan menunjukkan hubungan antar entitas pada Sistem Informasi Surat yang nantinya digunakan untuk perancangan basis Data. Adapun relasi basis Data yang terdapat pada Sistem Informasi pengelolaan surat masuk dan surat keluar pada Dinas Pertaian Kota Ternate sebagai berikut: 


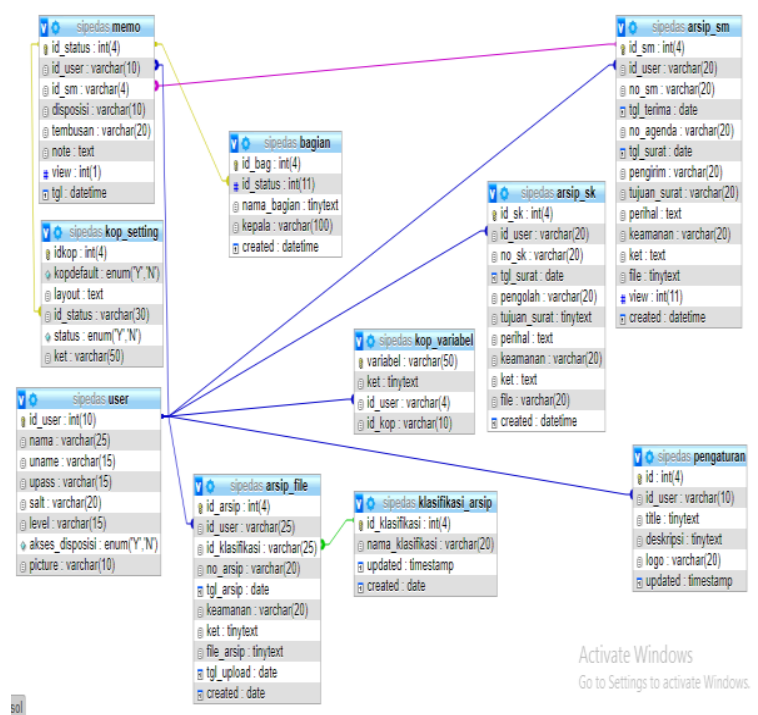

Gambar 7. Relasi Antar Tabel

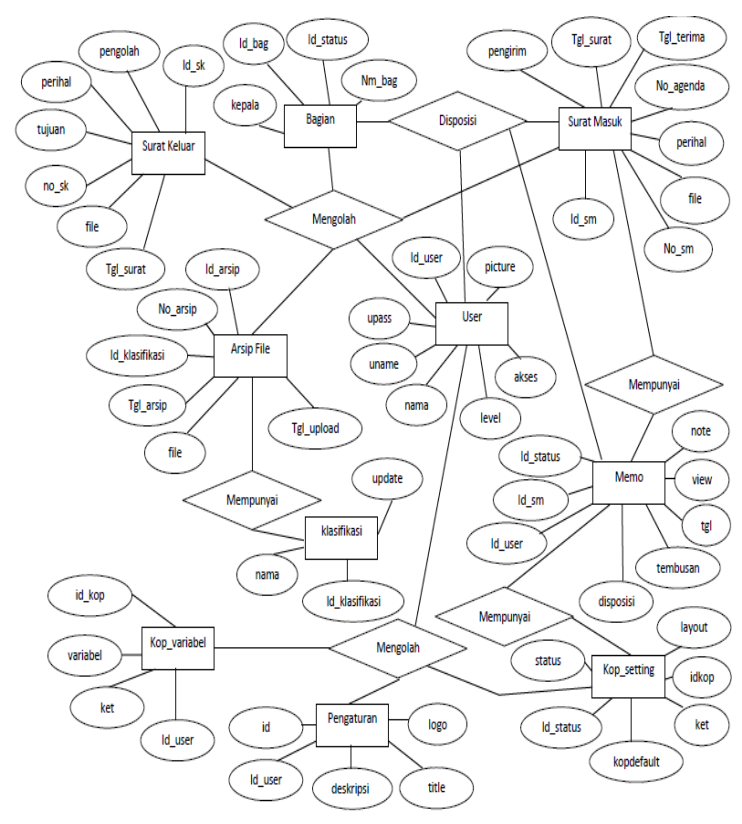

Gambar 8. ERD Persuratan

\section{IMPLEMENTASI DAN PEMBAHASAN}

Halaman pertama kali sebelum user masuk ke dalam Sistem adalah halaman login, halaman ini dirancang supaya user yang menggunakan Sistem adalah user yang berhak dalam menginput Data.

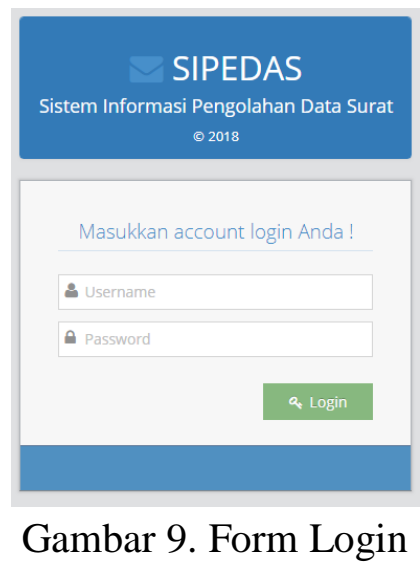

Setelah proses login user akan langsung ke halaman utama aplikasi, tampilan halan utama tergantung level user, umumnya pada halaman utama terdapat header, isi dan footer. Pada header terdapat nama aplikasi, identitas user yang sedang login dan identitas instansi seperti nama, alamat dan logo instansi. Pada isi terdapat menu-menu dan pada footer terdapat copyright aplikasi.

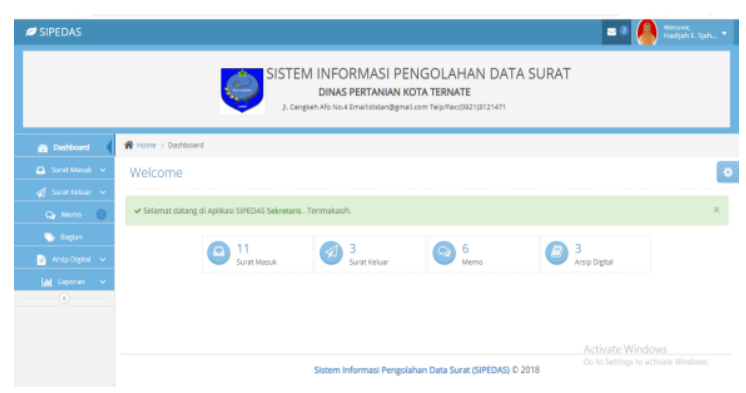

Gambar 10. Form menu utama

Pada Sistem ini terdapat form input Data surat masuk yang berfungsi sebagai tempat menginput Data surat masuk.

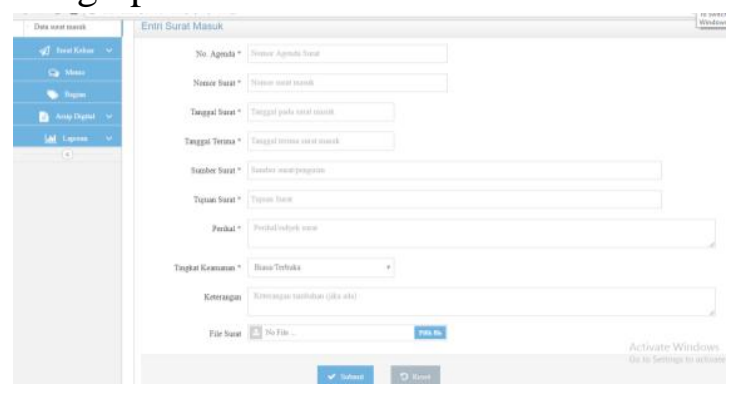

Gambar 11. Form Surat Masuk 


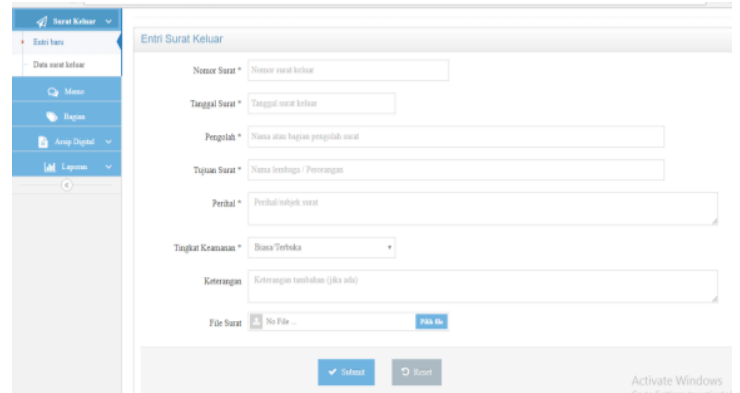

Gambar 12. Form Surat Keluar

Pada Sistem ini terdapat form input disposisi berdasarkan surat masuk yang berfungsi tempat menginput Data disposisi ke bagian-bagian. Form ini hanya dapat diakses oleh user dengan level kadis

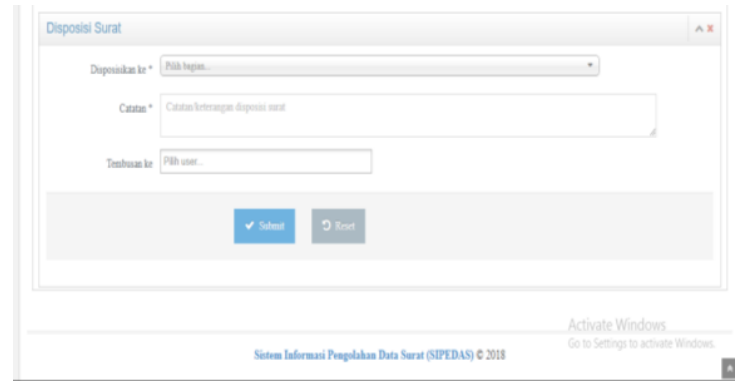

Gambar 13. Form Disposisi

Pada Sistem ini terdapat konfigurasi aplikasi untuk mengatur deskripsi kantor, alamat dan juga kop disposisi

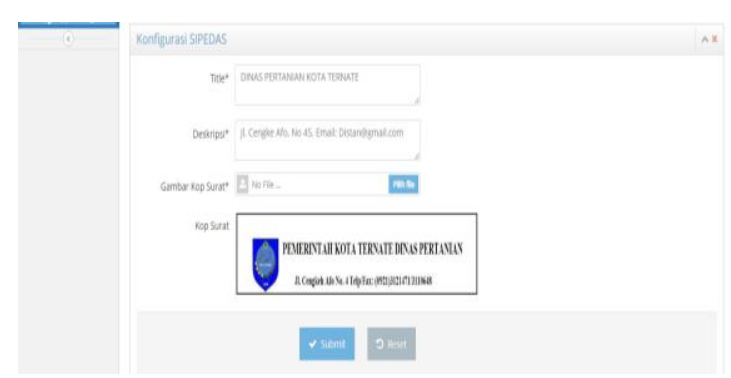

Gambar 14. Form Konfigurasi

Pada Output Surat Masuk menampilkan data-data surat masuk yang telah diinput, pada halaman ini bisa diadakan proses edit, hapus dan review data surat masuk.

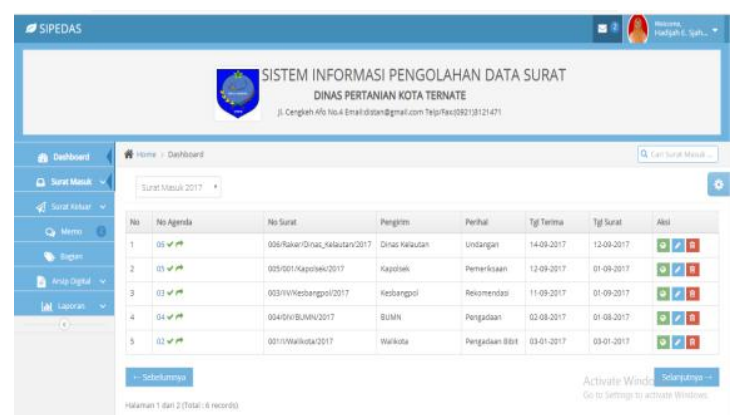

Gambar 15 Output Surat Masuk

Pada Output Surat Keluar menampilkan data-data surat keluar yang telah diinput, pada halaman ini bisa diadakan proses edit, hapus dan data surat keluar

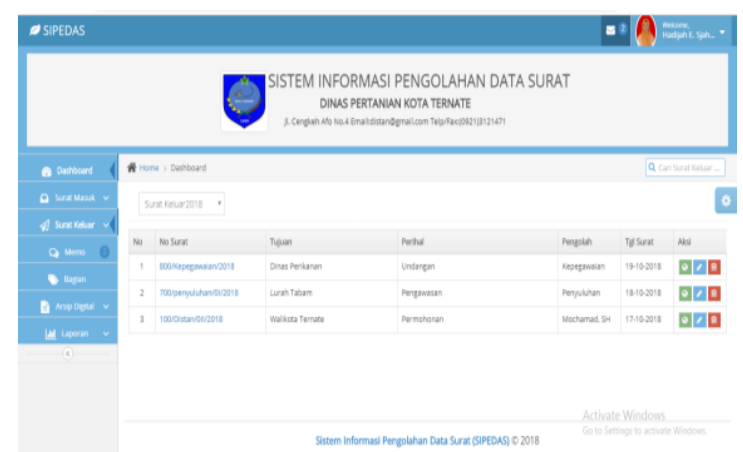

Gambar 16 Output Surat Keluar

Pada Output Disposisi menampilkan data-data surat masuk yang telah didisposisikan, pada halaman ini bisa diadakan proses edit, hapus dan data surat keluar

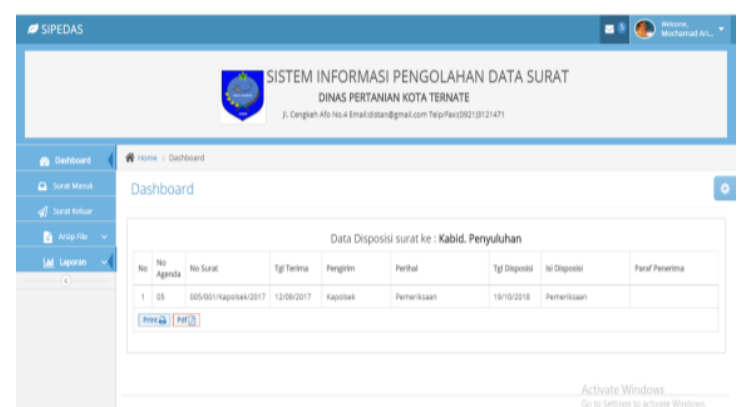




\section{Gambar 17 Output laporan Disposisi}

Berikut adalah lembaran disposisi yang siap cetak

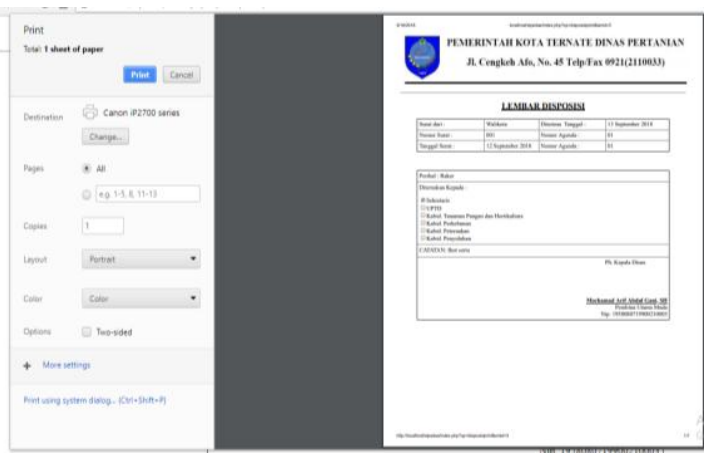

Gambar 18. Hasil Cetak Data Disposisi

\section{KESIMPULAN}

1. Dalam pengembangan Sistem digunakan bahasa pemrograman $P H P, M y S Q L$ sebagai basis Datanya, Style Programming menggunakan OOP dengan konsep Model View Controller MVC, Desain Template menggunakan HTML5, CSS3 dan Bootstrap Framework..

2. Sistem Informasi Manajemen Surat ini mempunyai beberapa keunggulan yaitu tersedianya fitur disposisi yang dapat digunakan untuk melakukan disposisi surat. Hasil disposisi surat dapat cetak langsung melalui aplikasi ke perangkat printer atau di export dalam format PDF.

3. Bisa menghasilkan Informasi mengenai Data surat yang masuk dan keluar dan bisa melakukan proses pencarian Data surat masuk dan keluar dalam waktu yang cepat.

\section{Saran}

1. Saran pengembangan yang dapat dilakukan adalah penerapan Teknologi terbaru pada Sistem Informasi Manajemen surat ini dapat diakses secara mul- tiplatform pada semua jenis perangkat dan juga browser. Selain itu untuk pengembangan diharapkan bisa menambahkan fitur sehingga proses pengiriman surat antar internal/external kantor dapat dilakukan secara online.

2. Diharapkan partisipasi dari pihak kantor Dinas Pertanian untuk memelihara dan memperbaharui Sistem Informasi website ini kedepannya.

3. Ketepatan dalam proses pengisian Data perlu diperhatikan agar tidak terjadi kesalahan dalam proses pengisian Data karena dapat berakibat fatal dalam proses pengolahan Informasi yang disampaikan.

\section{DAFTAR PUSTAKA}

Anhar. 2010. PHP \& MySql Secara Otodidak. Jakarta: PT TransMedia

Abdul Kadir. 2014. Pengenalan Sistem Informasi Edisi Revisi. Andi.Yogyakarta

Bunafit Nugroho. 2004. PHP dan MySQL dengan editor Dreamweaver $M X$. ANDI Yogyakarta, Yogyakarta.

Fathansyah, 2015. Basis Data. Informatika Bandung. Bandung

Moleong L. J, 2013. Metodologi Penelitian Kualitatif. ISBN 979-514-051-5, PT. Remaja Rosdakarya, Bandung.

Tata Sutabri. 2012. Analisis Sistem Informasi. Andi. Yogyakarta.

Wursanto, 1991, Kearsipan 1, Yogyakarta : Kanisius Yogyakarta

Darlianto A \& Permana I, 2013. Sistem Informasi Pencatatan Surat Masuk pada Kantor Camat Kabupaten Kampar Provinsi Riau, Vol. 2, No. 1 e-ISSN 2502-8995 p-ISSN 2460-8181. Akses internet via: (http://ejournal.uinsuska.ac.id/index.php/RM SI/article/download/1783/1320, diakses tanggal 24 Mei 2018 ). 
Dewi Leyla Rahma, Perancangan Aplikasi Sistem Persuratam Berbasis Web Pada PT. Dwi Pilar Pratama, Faktor Exacta, Vol 7 No 3 Tahun 2014, e-ISSN: 2502-339X

Masykur F, Atmaja I.M.P, 2015. Sistem Administrasi Pengelolaan Arsip Surat Masuk dan Surat Keluar Berbasis Web pada SMK Negeri 1 Magetan, Volume 4 No 3-Juli 2015-ijns.org IJNS-. Akses internet via: (http://ijns.org/journal/index.php/ijns/article/ download/1336/1324, diakses tanggal 25 April 2018).

Sugiharti E \& Triliani S.E, 2014. Perancangan Aplikasi Surat Masuk dan Keluar pada PT. Angkasa Pura 1 Semarang, Vol. 1, No. 1. ISSN 2407-7658.

Syafriadi 2016. Analisis Dan Perancangan Sistem Informasi Pengelolaan Surat Pada Universitas Cokroaminoto Palopo. Volume 7 No 4 - 2015 - speed.web.id. Akses internet via:(https://journal.uncp.ac.id/index.php /proceding/article/view/452/387, diakses tanggal 24 Mei 2018).

Triyono \& Samopa F \& Burhan U, 2013 JURNAL TEKNIK POMITS Vol. 2, No. 2 ISSN: $\quad 2337-3539 \quad$ (2301-9271 Print). Akses internet via: (http://download.portalgaruda.org/article.ph $\mathrm{p}$ ?article $=89111 \& \mathrm{val}=4186$, diakses tanggal 24 Mei 2018). 